\title{
Uma potente arma contra a opressão: a poesia - de longo alcance - de Vinicius de Moraes
}

\author{
Adriana Rodrigues Machado*
}

\begin{abstract}
Resumo: Partindo da biografia de Vinicius de Moraes, elaborada por José Castello, especificamente sobre o episódio que narra o momento em que o poeta recebe a notícia de que no Brasil fora instaurado o AI-5, pretendemos mostrar a força do discurso poético enquanto um ato de resistência, de repúdio a toda forma de opressão. Num momento frágil da história brasileira, num ato de coragem, o poeta faz ecoar em solo lusitano o sentimento universal de amor à pátria.
\end{abstract}

Palavras-chave: Poesia; Pátria; Ditadura; Portugal; Vinicius de Moraes.

\begin{abstract}
This text intends to point out the strength of the poetic speech as an act of resistance and disavowal regarding every form of oppression. The article deals with Vinicius de Moraes' biography, elaborated by Jose Castello, specifically with the episode that tells about the moment in which the poet gets to know about the establishment of AI-5 in Brazil. In a fragile moment of the Brazilian history, the poet displays courage and helps spread the universal feeling of love for the motherland in Portuguese soil.
\end{abstract}

Keywords: Poetry; Motherland; Dictatorship; Portugal; Vinicius de Moraes

Tomando como ponto de partida a biografia de Vinicius de Moraes, elaborada por José Castello - O Poeta da Paixão —, destacamos um episódio, em especial, para mostrar toda a força e a amplitude da sua poética.

Estamos em 1968. Vinicius de Moraes exerce a função de diplomata de carreira e, ao mesmo tempo, de show-man da música popular brasileira. Está em Portugal, exatamente em um quarto de hotel em Lisboa, quando recebe a notícia de que em seu país algo de muito grave estava acontecendo. É dia 13 de dezembro de 1968. No Brasil é decretado o ato institucional $\mathrm{n}^{\circ} .5$ - medida extrema do regime militar que vem lançar o país num longo período de opressão.

Os repórteres que o procuram, embaralhando nomes e informações, conseguem lhe dizer somente o essencial. Vinicius, sem entender exatamente o que está se passando, mas já muito assustado, procura saber notícias do amigo Rubem Braga que está no Rio de Janeiro. Corre para um telefone e fica sabendo apenas que ele viajou, sem maiores informações.

\footnotetext{
* Adriana Rodrigues Machado cursa o sétimo semestre do curso de Letras na Universidade Federal do Rio Grande do Sul. Publicou o ensaio "Crime e Castigo: a culpa como o próprio inferno", nos Cadernos do IL (Instituto de Letras da UFRGS) n. 28/29, p. 9-13, dez. 2004.
} 
Também procura saber de Otto Lara Resende, que ocupa naquele momento o posto de adido cultural em Lisboa, mas não consegue nenhuma notícia. À noite, mesmo abatido e bastante preocupado com os amigos, vai cumprir o seu papel no teatro. Seu show, junto com Baden Powell e a cantora Márcia, estreara havia três dias. Percebendo que Márcia está visivelmente amedrontada, Vinicius a encara e diz: "Não fique assim. Não adianta". O show deve terminar, como sempre, com o "Canto de Ossanha", uma das músicas mais famosas que compôs com Baden Powell. Portugal ainda está sob o regime férreo de Marcelo Caetano, uma ditadura fascista sedimentada por Salazar. A Rádio e Televisão Portuguesa, sem poder escapar do tema 'Brasil', manda uma equipe para o teatro para fazer um tape do show. Vinicius não se intimida. Antes de começar o "Canto de Ossanha", interrompe o show, e começa: "Eu hoje gostaria de dizer a vocês umas palavras de muita tristeza, no meu país foi instaurado, hoje, o ato institucional $\mathrm{n}^{\circ}$. 5. Pessoas estão sendo perseguidas, assassinadas, torturadas. Por isso, quero ler um poema" (CASTELLO, 1994, p. 282-284). Abre um exemplar de sua Antologia poética, guardado sob a garrafa de uísque e, enquanto Baden Powel começa a dedilhar o Hino Nacional Brasileiro, lê:

A minha pátria é como se não fosse, é íntima/ Doçura e vontade de chorar; uma criança dormindo/ É minha pátria. Por isso, no exílio/ Assistindo dormir meu filho/ Choro de saudades de minha pátria". "Trata-se do magnífico 'Pátria minha', um dos mais belos poemas escritos por Vinicius de Moraes". A platéia se extasia diante de versos como esses: "Não te direi o nome, pátria minha/ Teu nome é pátria amada, é patriazinha/ Não rima com mãe gentil/Vives em mim como uma filha, que és/ Uma ilha de ternura; a Ilha/ Brasil, talvez. (CASTELLO, 1994, p. 282-284).

"A leitura de Pátria minha ficará na memória dos portugueses como uma das mais bem-acabadas expressões que puderam conhecer do amor à liberdade" (CASTELLO, 1994, p. 282-284), ressalta o biógrafo.

Na noite seguinte à Revolução dos Cravos, alguns anos depois, em 1974 - quando, finalmente, o povo português se vê liberto após 48 anos de uma violenta opressão —, a Rádio e Televisão Portuguesa, tomada pela euforia, retirará o tape de seus arquivos e o reprisará.

O discurso poético é analisado aqui, paradoxalmente, como um instrumento ofensivo contra uma atitude autoritária e violenta. Como um representante de um país que outrora fora colonizado por aquele mesmo solo que agora o recebe, o poeta rompe fronteiras através de seus versos; rompe com a identidade nacional enquanto universaliza o sentimento de amor à pátria, fazendo com que outras vozes, em um outro espaço-tempo, se apropriem desse mesmo discurso, incitando e celebrando a liberdade, a democracia, e a soberania de um povo; tomando também na sua universalidade, um outro sentimento igualmente caro à alma portuguesa: a saudade. Saudade de um passado glorioso onde Portugal conhecia a liberdade. 
Lembrando o conceito bakhtiniano de texto como tecido de redes discursivas, podemos afirmar que a linguagem poética aqui ecoa, multiplica-se, ressignifica-se amplamente.

Em sua primeira crônica, intitulada "A Transfiguração pela Poesia", publicada em 1946, num período em que o Brasil se redemocratizava e que o mundo ainda chorava os mortos da $2^{\text {a }}$. Grande Guerra, ele dizia: "Sofre o mundo da transformação da pá em fuzil, do arado em tanque de guerra, da imagem do semeador que semeia na do autômato com seu lança-chamas, de cuja sementeira brotam solidões. A esse mundo, só a poesia poderá salvar, e a humildade diante da sua voz [...]" (MORAES, 2004, p.702).

Pátria minha saiu como um pequeno livro em 1949, numa edição de 55 exemplares, feita pelo também diplomata e poeta João Cabral de Melo Neto, em sua prensa manual quando morava em Barcelona, sob o selo O Livro Inconsútil. E como inconsútil é aquilo que é feito de uma só peça, aquilo que é inteiriço, que não sofre interrupção, nada mais justo que fazermos a leitura, na íntegra, de Pátria minha.

\section{A minha pátria é como se não fosse, é íntima}

Doçura e vontade de chorar; uma criança dormindo

É minha pátria. Por isso, no exílio

Assistindo dormir meu filho

Choro de saudades de minha pátria.

Se me perguntarem o que é a minha pátria, direi:

Não sei. De fato, não sei

Como, por que e quando a minha pátria

Mas sei que a minha pátria é a luz, o sal e a água

Que elaboram e liquefazem a minha mágoa

Em longas lágrimas amargas.

Vontade de beijar os olhos de minha pátria

De niná-la, de passar-lhe a mão pelos cabelos...

Vontade de mudar as cores do vestido (auriverde!) tão feias

De minha pátria, de minha pátria sem sapatos

E sem meias, pátria minha

Tão pobrinha!

Porque te amo tanto, pátria minha, eu que não tenho

Pátria, eu semente que nasci do vento

$\mathrm{Eu}$ que não vou e não venho, eu que permaneço

Em contato com a dor do tempo, eu elemento

De ligação entre a ação e o pensamento

Eu fio invisível no espaço de todo adeus

Eu, o sem Deus!

Tenho-te no entanto em mim como um gemido

De flor; tenho-te como um amor morrido

A quem se jurou; tenho-te como uma fé

Sem dogma; tenho-te em tudo em que não me sinto a jeito

Nesta sala estrangeira com lareira

E sem pé-direito.

Ah, pátria minha, lembra-me uma noite no Maine, Nova Inglaterra 
Quando tudo passou a ser infinito e nada terra

E eu vi alfa e beta de Centauro escalarem o monte até o céu

Muitos me surpreenderam parado no campo sem luz

À espera de ver surgir a Cruz do Sul

Que eu sabia, mas amanheceu...

Fonte de mel, bicho triste, pátria minha

Amada, idolatrada, salve, salve!

Que mais doce esperança acorrentada

O não poder dizer-te: aguarda...

Não tardo!

Quero rever-te, pátria minha, e para

Rever-te me esqueci de tudo

Fui cego, estropiado, surdo, mudo

Vi minha humilde morte cara a cara

Rasguei poemas, mulheres, horizontes

Fiquei simples, sem fontes.

Pátria minha... A minha pátria não é florão, nem ostenta

Lábaro não; a minha pátria é desolação

De caminhos, a minha pátria é terra sedenta

E praia branca; a minha pátria é o grande rio secular

Que bebe nuvem, come terra

E urina mar.

Mais do que a mais garrida a minha pátria tem

Uma quentura, um querer bem, um bem

Um libertas quae sera tamen

Que um dia traduzi num exame escrito:

"Liberta que serás também"

E repito!

Ponho no vento o ouvido e escuto a brisa

Que brinca em teus cabelos e te alisa

Pátria minha, e perfuma o teu chão...

Que vontade me vem de adormecer-me

Entre teus doces montes, pátria minha

Atento à fome em tuas entranhas

E ao batuque em teu coração.

Não te direi o nome, pátria minha

Teu nome é pátria amada, é patriazinha

Não rima com mãe gentil

Vives em mim como uma filha, que és

Uma ilha de ternura: a Ilha

Brasil, talvez.

Agora chamarei a amiga cotovia

E pedirei que peça ao rouxinol do dia

Que peça ao sabiá

Para levar-te presto este avigrama:

"Pátria minha, saudades de quem te ama...

(MORAES, 2004, p. 359-361)

Quanto ao emprego dos diminutivos - condenado por alguns críticos e defendido por outros como necessidade estética - , é interessante registrar que o poeta o justificava, de uma maneira bastante singela, dizendo: "gosto dos diminutivos, porque nada no diminutivo faz mal" (CASTELLO, 1994, p.17). 
Portanto, o mito do 'poetinha', no sentido pejorativo, tratando-se de Vinicius de Moraes, é totalmente inadequado.

Reforçando essa idéia, Junqueira (2004, p. 163) refere-se ao poeta em um artigo intitulado "Vinicius de Moraes: Língua e Linguagem Poética" dessa forma:

Chamá-lo, como hoje ainda o chamam, ainda que carinhosamente, de poetinha não condiz em absoluto com a grandeza de seus versos. Cumpre assim que resgatemos, já e já, sua condição de alto poeta, de poeta que transcendeu os limites do tempo e que, numa antevisão de sua trajetória rumo à posteridade, escreveu um dia:

Ando onde há espaço:

- Meu tempo é quando. (JUNQUEIRA, 2004, p. 163.)

Para encerrarmos, reportamo-nos à já citada crônica "A Transfiguração pela Poesia", na qual, referindo-se à voz da poesia, o poeta dizia:

Não se trata de desencantá-la, porque creio na sua aparição espontânea, inevitável. Surgirá de vozes jovens fazendo ciranda em torno de um mundo caduco; de vozes de homens simples, operários, artistas, lavradores, marítimos, brancos e negros, cantando o seu labor de edificar, criar, plantar, navegar um novo mundo; de vozes de mães, esposas, amantes e filhas, procriando, lidando, fazendo amor, drama, perdão. E contra essas vozes não prevalecerão as vozes ásperas de mando dos senhores nem as vozes soberbas das elites. Porque a poesia ácida lhes terá corroído as roupas. E o povo então poderá cantar seus próprios cantos, porque os poetas serão em maior número e a poesia há de velar". (MORAES, 2004, p. 702)

\section{Referências}

CASTEllo, José. Vinicius de Moraes: o poeta da paixão. Uma biografia. São Paulo: Companhia das Letras, 1994.

CUNHAL, Álvaro. A Revolução dos Cravos: abril de 1974 - novembro de 1975. In: COGGIOLA, Osvaldo (Org.). Espanha e Portugal: o fim das ditaduras. São Paulo: Xamã, 1995. p. 139-152.

JUNQUEIRA, Ivan. Vinicius de Moraes: Língua e Linguagem Poética. In: FERRAZ, Eucanaã. (Org.) Vinicius de Moraes: poesia completa e prosa - volume único. (Fortuna crítica). Rio de Janeiro: Nova Aguilar, 2004.

MACHADO, Irene. A. Os gêneros e a ciência dialógica do texto. In: FARACO, Carlos Alberto, TEZZA, Cristóvão, CASTRO, Gilberto de. (Orgs.) Diálogos com Bakhtin. 3. ed. Curitiba: Editora da UFPR, 2001.

MORAES, Vinicius. Poesia completa e prosa. Organização de Eucanaã Ferraz. Rio de Janeiro: Nova Aguilar, 2004. 